\title{
C2C E-commerce Risk Assessment Based on AHP and Fuzzy Comprehensive Evaluation
}

\author{
Wei baolu ${ }^{\text {a, }}$, Dai Feng ${ }^{\text {a }}$, Liu jingxu ${ }^{\text {a }}$ \\ ${ }^{a}$ Institute of Information Engineering, Information Engineering University, Zhengzhou, china
}

\begin{abstract}
Firstly this paper gives an introduction to the current $\mathrm{C} 2 \mathrm{C}$ e-commerce transactions in China and gives a review of relevant theories and research. Then, we proposed a new method that AHP and fuzzy comprehensive evaluation method of combining, and discuss the methods used in this risk assessment of the feasibility of e-commerce transactions. Finally, an instance of the application of this method to assess the final results prove that the application of the method of assessment of such problems feasible.

With the rapid development of Internet, e-commerce as a new business model has achieved great development and progress which greatly changed the way people live and work, at the same time it gives a rise to the unlimited business opportunities. $\mathrm{C} 2 \mathrm{C}$ is one kind of the e-commerce transactions, Internet service providers that use of computer and network technology, used to provide paid or unpaid. E-commerce platform allows two parties (mainly for individual users) in its platform to bid independently, bargaining-based online trading patterns. In recent years, China's $\mathrm{C} 2 \mathrm{C}$ market in a rapid growth phase, this model has become the holder of a large number of small venture capital approach. However, due to the virtual nature of online transactions, buyers and sellers transaction process is often non-face environment in, on product quality, price and service and other aspects of information entirely on the buyer's estimate. Therefore, $\mathrm{C} 2 \mathrm{C}$ e-commerce system model is a clear system of information asymmetry, the potential risk is enormous. Asymmetric information in this trading environment, to ensure smooth transactions and reduce risk, the two sides of the credit problem is particularly prominent. Meanwhile, in the current transaction before the transaction, the risk prediction and assessment has become very important. Currently, e-commerce e-commerce credit risk has become a constraint to further development of the main obstacles.
\end{abstract}

Index Terms: E-commerce; Fuzzy comprehensive evaluation; Risk assessment

(C) 2011 Published by MECS Publisher. Selection and/or peer review under responsibility of the Research Association of Modern Education and Computer Science.

* Corresponding author.

E-mail address: weibaolu@126.com 


\section{Related research}

$\mathrm{C} 2 \mathrm{C}$ e-commerce transactions on the current risks of the research can be divided in to three categories.

One is its theoretical, conceptual analysis and development. For example: Paper [1] from the value of enterprises, profit target, revenue and cost way to obtain the mode of occurrence of the profit model of $\mathrm{C} 2 \mathrm{C} \mathrm{e}$ commerce site for the profit model of $\mathrm{C} 2 \mathrm{C}$ e-commerce sites to provide case study support; Paper [2] reasons for the rise of $\mathrm{C} 2 \mathrm{C}$ and $\mathrm{C} 2 \mathrm{C}$ Internet marketing analysis of the current situation and its prospects for the future development prospects.

Two is its introduction and compared of $\mathrm{C} 2 \mathrm{C}$ e-commerce transactions on the main site. For example: Paper [3] give a compare of the two largest $\mathrm{C} 2 \mathrm{C}$ website, for the background from the site, strategic positioning, business model, special services and other aspects of the success or failure analysis, how to analyze different parts of the site, buyers and sellers of consumer psychology, habits, and economic based differences, and adopt different strategies to attract more registered customers. Paper [4] analysis the failure of eBay and Taobao's success factors were discussed that competition is not just for the C2C website competition on the pricing strategy, or services, and transaction-related aspects of a full range of competition. "Demand" for $\mathrm{C} 2 \mathrm{C}$ e-commerce site is critical. China $\mathrm{C} 2 \mathrm{C}$ website has no real sense of the winners, because they lack profit model suitable for China.

Three is to propose an assessment can be applied to methods in this area, through the establishment of evaluation index system to evaluate a particular instance. For example, Paper [5] gives an improved credit scoring method. The methods range of commodity prices to a successful transaction distribution points, the use of points credit rating credit rating of different factors to the failure of the transaction points, can solve the credit cycle of hype and deception issues. Paper [6] Based on the existing credit evaluation model for C2C ecommerce research, the new credit score rating, credit evaluation index system was established. New model for the new traders to provide a more efficient transactions, further reduce the transaction risk, helping traders to make the right trading decisions. This paper is the third category.

\section{Related Method}

The Analytic Hierarchy Process was proposed by the United States Operations Research Professor TL.Saaty. It is a simple, flexible and practical method for multiple criteria decision making. Its algorithm is as follows [7]:

1. Matrix groups according to structural indicators.

2. Scored by expert.

3. Calculate the maximum eigenvector matrix, characteristic value.

4. Random consistency test, rounding to the vector did not pass the test.

5. Weight vector using the weighted arithmetic average method over the same criterion to determine the weight vector matrix group. Comprehensive evaluation, is something with multiple attributes, or the overall merits of the things affected by many factors make - one can reasonably attribute or combination of these factors, the overall evaluation.

Suppose $U=\left\{U_{1}, U_{2}, \cdots U_{n}\right\}$ is $n$ factors of the study, which is a key assessment of the objecte valuation index, we called $U$ as an index set. $V=\left\{v_{1}, v_{2}, \cdots, v_{m}\right\}$ is ${ }^{m}$ kind posed by the judge evaluation set. The number of the evaluation set is according to the needs of practical problems indentified by the decision makers subjective. Actually, most problems are fuzzy sets. So, the comprehensive evaluation is supposed an fuzzy subset $B=\left(b_{1}, b_{2}, \cdots, b_{m}\right) \in F(V)$ of $V, \mu_{B}\left(v_{k}\right)=b_{k}(k=1,2, \cdots, m)$. As a result, when power vector $W$ is given, corresponding to an integrated assessment for a given vector $B$.

Fuzzy comprehensive assessment of the general steps are as follows:

(1)Determine the factors set $U=\left\{U_{1}, U_{2}, \cdots, U_{n}\right\}$; 
(2)Determine the evaluation set $V=\left\{v_{1}, v_{2}, \cdots, v_{m}\right\}$;

(3)Determine the fuzzy evaluation matrix $R=\left(r_{i j}\right)_{n \times m}$;

Firstly, give each factor $U_{i}$ an evaluation $f\left(U_{i}\right)(i=1,2, \cdots, n)$, so we can get an fuzzy mapping $f$ from $U$ to $V$ :

$$
\begin{aligned}
& f: U \rightarrow F(U) \\
& U_{i} \rightarrow f\left(U_{i}\right)=\left(r_{i 1}, r_{i 2}, \cdots, r_{i m}\right) \in f(V)
\end{aligned}
$$

Secondly, from $f$ we can induced the fuzzy relation $R_{f} \in F(U \times V)$,

$$
R_{f}\left(U_{i}, v_{j}\right)=f\left(u_{i}\right)\left(v_{j}\right)=r_{i j}(i=1,2, \cdots, n ; j=1,2, \cdots, m)
$$

We can determine the fuzzy evaluation $R=\left(r_{i j}\right)_{n \times m}$, called $(U, V, R)$ fuzzy comprehensive evaluation model.

(4) Comprehensive:

For weight $W=\left(W_{1}, W_{2}, \cdots, W_{n}\right) \in F(U)$, according $M(\wedge, \vee)$ we can obtain the comprehensive evaluation results.

$$
B=W \bullet R\left(o r b_{j}=\vee_{i=1}^{n}\left(W_{i} \wedge r_{i j}\right), j=1,2, \cdots, m\right)
$$

\section{Evauation Index System}

Principles of determine evaluation indicators:

1 Establishment of credit evaluation system is to examine the fundamental purpose of $\mathrm{C} 2 \mathrm{C}$ e-commerce transactions subject credit for other body involved in the transaction or the potential users visit, so, the contents of the credit rating index system to comprehensively reflect the impact of the credit assessment of the object elements of the appraisal on the basis of past credit status can predict future trends.

2 Credit assessment indicators to accurately reflect the true subject of e-commerce transactions credit, index system and method of calculation can not favor any party involved in the transaction, assessment indicators, methods and standards can not be based on the assessment of the main interests of personal preference or random change.

3 Selected to reflect the true credit transaction are the main representative indicators, and the number of indicators should not be too much point in time should be trading, transaction codes, payment records, which qualify for special $\mathrm{C} 2 \mathrm{C}$ e-commerce indicators incorporated in the credit evaluation index system.

4 Principle of hierarchy in a multi-index evaluation system, the different indicators are closely related, constitute an indicator of class, so in practice tend to classify targets, constitute different levels, so, ecommerce credit evaluation index selection as far as possible from the different levels credit assessment covers elements of principal transactions, in order to really reflect its credit standing.

5 Evaluation indicators must be simple and standardized, should be able to make the different between subjects with comparable transactions, and easy to implement in actual use and master; assessment data should be easy to collect, the purpose of computing and statistics, the accuracy, reliability, easy to maintain.

The contents of evaluation indicators:

Screening based on the principle of the evaluation index, drawing on existing credit assessment on the basis of research results, the author of $\mathrm{C} 2 \mathrm{C}$ e-commerce transactions summarized the main factors of the main credit for the basic credit, professional credit and trade credit in three aspects. On this basis, combined with the personal credit investigation of the relevant results of the evaluation study to build a $\mathrm{C} 2 \mathrm{C}$ e-commerce as shown in Figure 1 credit comprehensive evaluation index system II: 


\section{Application of the algorithms}

C2C transactions involved assuming an age of Internet users is 31 years old male, married with children, masters degree, has full ownership of their own homes, 30 million from a bank loan for the purchase of second homes; ten working in a university years, and no administrative duties, intermediate grade, monthly income of 3,000 yuan; because of work and learning needs, in the recent period of 3 years, the man every year into the C2C site to buy or exchange books with others, software or electronic products, one-year deal number not more than 10 times the amount of each transaction is 200 yuan, $100 \%$ received high praise, often clearing the way third-party payment.

Using AHP and fuzzy comprehensive evaluation score, Calculated weights using the AHP, Judge matrix:

$$
\begin{aligned}
A & =\left[\begin{array}{ccc}
1 & 2 & 0.5 \\
0.5 & 1 & 0.25 \\
2 & 4 & 1
\end{array}\right] \\
A_{1} & =\left[\begin{array}{ccccc}
1 & 0.2 & 0.2 & 1 & 0.33 \\
5 & 1 & 0.2 & 0.2 & 1 \\
5 & 5 & 1 & 0.2 & 1 \\
1 & 5 & 2 & 1 & 3 \\
3 & 1 & 1 & 0.33 & 1
\end{array}\right] \\
A_{2} & =\left[\begin{array}{ccccc}
1 & 2 & 2 & 1 & 3 \\
0.5 & 1 & 1 & 0.5 & 0.66 \\
0.5 & 1 & 1 & 0.5 & 0.66 \\
1 & 2 & 2 & 1 & 3 \\
0.33 & 1.5 & 1.5 & 0.33 & 1
\end{array}\right] \\
A_{3} & =\left[\begin{array}{ccccc}
1 & 2 & 1 & 1 & 0.5 \\
0.5 & 1 & 2 & 2 & 4 \\
1 & 0.5 & 1 & 1 & 2 \\
1 & 0.5 & 1 & 1 & 2 \\
2 & 0.25 & 0.5 & 0.5 & 1
\end{array}\right] \\
W_{1} & =\left[\begin{array}{lllll}
0.28 & 0.57 & 0.15
\end{array}\right] \\
W_{1} & =\left[\begin{array}{lllll}
0.36 & 0.07 & 0.07 & 0.36 & 0.14
\end{array}\right] \\
W_{2} & =\left[\begin{array}{lllll}
0.12 & 0.24 & 0.24 & 0.12 & 0.38
\end{array}\right] \\
W_{3} & =\left[\begin{array}{lllll}
0.18 & 0.36 & 0.18 & 0.18 & 0.1
\end{array}\right]
\end{aligned}
$$

All of the above is meet the consistency $C R<0.1$.

These results can be obtained from the second layer and the relative weight of indicators shown in Table 1 ranking. 


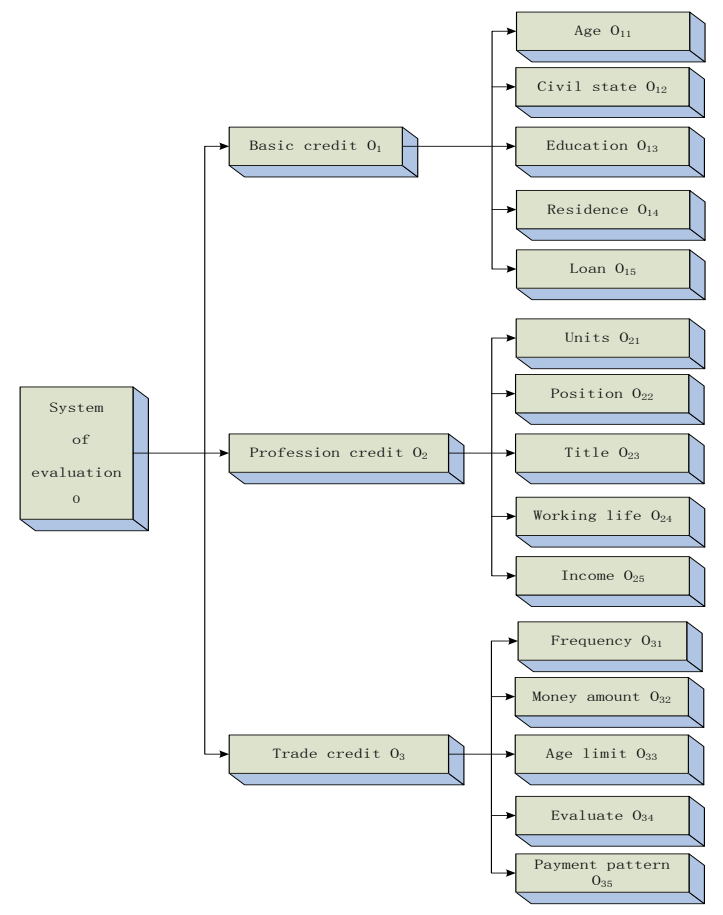

Fig. 1 The evaluation index system

Table 1, risk weight and ranking of the secondary indicators

\begin{tabular}{|c|c|c|}
\hline $\begin{array}{c}\text { Secondary } \\
\text { indicators }\end{array}$ & Risk weight & ranking \\
\hline $\mathrm{O}_{11}$ & 0.36 & 2 \\
\hline $\mathrm{O}_{12}$ & 0.07 & 13 \\
\hline $\mathrm{O}_{13}$ & 0.07 & 13 \\
\hline $\mathrm{O}_{14}$ & 0.36 & 2 \\
\hline $\mathrm{O}_{15}$ & 0.14 & 10 \\
\hline $\mathrm{O}_{21}$ & 0.12 & 11 \\
\hline $\mathrm{O}_{22}$ & 0.24 & 5 \\
\hline $\mathrm{O}_{23}$ & 0.24 & 5 \\
\hline $\mathrm{O}_{24}$ & 0.12 & 11 \\
\hline $\mathrm{O}_{25}$ & 0.38 & 1 \\
\hline $\mathrm{O}_{31}$ & 0.18 & 7 \\
\hline $\mathrm{O}_{32}$ & 0.36 & 2 \\
\hline $\mathrm{O}_{33}$ & 0.18 & 7 \\
\hline $\mathrm{O}_{34}$ & 0.18 & 7 \\
\hline $\mathrm{O}_{35}$ & 0.1 & 15 \\
\hline & & \\
\hline
\end{tabular}


Using the form of the questionnaire, ask 20 experts to judge the weight of each index. After the evaluation results have been overall integrated fuzzy relationship matrix:

$$
R=\left[\begin{array}{ccccc}
0.10 & 0.15 & 0.4 & 0.33 & 0.22 \\
0.05 & 0.05 & 0.1 & 0.45 & 0.4 \\
0.05 & 0.25 & 0.5 & 0.4 & 0.15 \\
0 & 0.10 & 0.2 & 0.5 & 0.2
\end{array}\right]
$$

The final total result of fuzzy comprehensive evaluation:

$$
B=W * R=\left[\begin{array}{lllll}
0.1 & 0.25 & 0.4 & 0.333 & 0.222
\end{array}\right]
$$

The maximum level of 0.4 in determining the "medium" of the principle of maximum degree, that the level of Internet users is in the assessment of e-commerce transactions.

\section{Summary}

AHP and fuzzy comprehensive evaluation of the risk assessment $\mathrm{C} 2 \mathrm{C}$ e-commerce transactions to resolve the assessment of quantitative assessment of qualitative indicators of the difficulty. By this method, you can calculate the relative risk factors and the $\mathrm{C} 2 \mathrm{C}$ e-commerce transaction system's security risk level. By identifying the risk level of $\mathrm{C} 2 \mathrm{C}$ e-commerce transactions to increase awareness of security risks; to determine the relative risk factor, you can control risk, reduce risk and transfer risk to make the right judgments. Example proves that the method has a strong scientific and effective, can be well applied to risk assessment of $\mathrm{C} 2 \mathrm{C}$ e-commerce transactions.

\section{Acknowledgements}

This work is supported by the National Social Science Foundation of China (No. 09\&ZD014)

\section{References}

[1] Wang Jie-shuang. Analysis C2C e-commerce site profit model of eBay [J].Management Observer 2009, 6(1):252. (in Chinese)

[2] Huang Min, Zhou Nan. Journal of Guangxi University.2008, 30(30):158-159. (in Chinese)

[3] Zhang Wei-wei, Liu Chon Inner Mongolia Science Technology \& Economy.2008, 24(178):79-80. (in Chinese)

[4] Zhou Geng. The success of Taobao and eBay Case Study [J]. Modern Management Science.2008, 3(1):62-63. (in Chinese)

[5] Li Rui-xuan. Research on credit counting and risk evaluation for $\mathrm{C} 2 \mathrm{C}$ e-commerce [J].Journal on Communications.2009, 30(7):78-85. (in Chinese)

[6] Tao Yang, Gong Xiao-jing. Research on C2C [J].China Management Informationization.2008, 11(7):8289. (in Chinese)

[7] Faruqi F A. Non-linear mathematical model for integrated global positioning inertial navigation system [J]. Applied Mathematics and computation, 2000,115: 191-212. (in Chinese) 